\title{
Nurturing Intrapreneurship to Enhance Job Performance: The Role of Pro-Intrapreneurship Organizational Architecture
}

\author{
Noor Hazlina Ahmad, Aizzat Mohd Nasurdin and Siti Rohaida Mohamed Zainal
}

Universiti Sains Malaysia, Malaysia

\begin{abstract}
Following the needs to ingrain intrapreneurial spirit among Malaysian workforce, as highlighted in the National Economic Advisory 2010, the aim of this study is to identify the organizational architecture that can be designed to foster such behaviour which could subsequently lead to better job performance. Specifically, this study examines the effects of five dimensions of pro-intrapreneurship organizational architecture; namely, "management support", "work discretion", "reward and reinforcement", "organizational boundaries" and "time availability" on intrapreneurial behaviour which was then regressed to the job performance. A sample of 263 employees consisting of engineers and managers working in multinational companies participated in this study. The findings were tested using structural equation modeling procedure. In general, the results indicate that except for "organizational boundaries", other organizational architecture namely "management support", "work discretion", "reward and reinforcement" and "time availability" were found to have positive significant effects on intrapreneurship. In addition, intrapreneurial behaviour is found to be positively related to job performance. In short, it can be surmised forming an internal ecosystem that is conducive for the workforce to behave intrapreneurially is a wise step to foster innovativeness culture that could subsequently be translated into a long term growth and sustainability of the organization.
\end{abstract}

Keywords: Intrapreneurship; Job Performance; Malaysia; Innovativeness.

\section{Introduction}

The recent scenario in the commercial landscape has witnessed the increasing pressure exerted on organizations to compete towards organizational sustainability. The businesses now should be cognizant of the fact that past economic success is no longer a guarantee of future success. Various measures have been taken by organizations to face the stiff competition; and one of the means is via invigorating intrapreneurial spirit among the workforce to enhance productivity and job performance. Intrapreneurship is perceived to be important, not only because it assists organizations to obtain a better competitive position but also contributes to the economy of a country at large. Having said that, even though it has been acknowledged that fostering intrapreneurial behaviour is imperative, the research on intrapreneurship remains uncharted, particularly in the context of Malaysia.

As reported by National Economic Advisory 2010, Malaysia's strategic plan to transform its economy focuses on strengthening and intensifying human capital development. Among the strategic thrusts proposed is to intensify human capital and to equip human resources with necessary competencies and encourage entrepreneurial initiatives to make certain that the private sector is the vanguard of the economic development. The emphasis on fostering entrepreneurial spirit among

Copyright (C) 2012 Noor Hazlina Ahmad, Aizzat Mohd Nasurdin and Siti Rohaida Mohamed Zainal. This is an open access article distributed under the Creative Commons Attribution License unported 3.0, which permits unrestricted use, distribution, and reproduction in any medium, provided that original work is properly cited. Contact author: Noor Hazlina Ahmad E-mail: hazlina@usm.my 
workforce in private sector is seen crucial to improve the competitiveness of the organization and subsequently enhance the competitiveness of the country. As for Malaysia, the declining trend in the ranking of Global Competitiveness Index from $21^{\text {th }}$ in $2008 / 2009$ to $26^{\text {th }}$ in year $2010 / 2011$ (World Economic Forum, 2011), is a preoccupying phenomenon. A mechanism to rectify this situation is via fostering innovativeness and entrepreneurship spirit among Malaysia workforce to enhance productivity and performance.

In line with the Malaysian government aspiration to transform its economy by fostering entrepreneurial initiatives, it is deemed timely that a study to be undertaken to understand the factors that contribute towards intrapreneurial behaviour among the workforce. Thus, the main objective of this study is to investigate the organizational architecture that could influence intrapreneurial behaviour and subsequently examine the effect of intrapreneurial behaviour on job performance.

\section{Literature Review and Conceptual Framework}

Intrapreneurship specifically refers to entrepreneurship behaviour exhibited within existing organizations that focuses on the employee initiatives in an organization to start or undertake something new although he or she is not being asked to do so (de Jong, J., Parker, S.K., Wennekers, S., \& Wui, C, 2011). Opportunity pursuit, resource acquisition, risk taking, proactiveness and innovativeness are believed to be the key elements of entrepreneurial behaviours in existing organizations (De Jong \& Wennekers, 2008). According to the authors, there are several important characteristics of intrapreneurs which include: (1) proactive individuals who are self-starters or having an initiative to generate new ideas; (2) individuals who find a way to pursue opportunities regardless of the resources controlled by them currently; and (3) individuals who undertake something considered "innovative" or "new" and their actions and behaviours often deviate from the customary ways of doing things in existing firms. It has been stressed that organizations should capitalize on their employees' ability to innovate in order to transform the organization to be more competitive (de Jong \& Hartog, 2007).

As stated, two core elements of innovative behaviours in contributing to the innovation process are idea generation and application. The first element encourages employees to explore the opportunity, identify the problem or performance gaps and try to produce the solutions. The second element allows the employees to implement the idea generated. Thus, in an organization, the workforce could play a vital role in the innovation process by demonstrating the application-oriented behaviour via efforts such as persuading or selling the ideas to others and devoting to developing, testing and commercialising their ideas. In bolstering intrapreneurial behaviour within an existing organization where the workforce has no absolute control over the resources, it has been argued that the commitment of the top management in developing or crafting an appropriate organizational architecture is vital. It is given that a supportive environment is believed to enable intrapreneurial behaviour among the workforce to flourish.

\section{Pro-Intrapreneurship Organizational Architecture and Intrapreneurial Behaviour}

As stated earlier, pro-intrapreneurship organizational architecture refers to important organizational architecture that could foster intrapreneurship behaviour among employees within an organization. It is believed that proper organizational structure including reward system needs to be in place so as to ensure that the structure is conducive to spur intrapreneurial behaviour among employees. As such, the subsequent section explores the five important prointrapreneurship organizational architecture that could foster intrapreneurship which include: (i) management support, (ii) work discretion, 
(iii) reward and reinforcement, (iv) time availability and organizational boundaries.

\section{Management Support}

Management support refers to the "willingness of the top-level managers to facilitate and promote entrepreneurial behaviour; including championing of innovative ideas and providing the resources people require to take entrepreneurial actions" (Kuratko, Ireland, Covin \& Hornsby, 2008, p. 703). The degree of willingness of management to promote the intrapreneurial behaviour in supporting the workforce has been considered as the best way to maximum outcome of corporate entrepreneurship (Bhardwarj, Sushil \& Momaya, 2007). A study conducted by Holt, Rutherford and Clohessy (2007) found that management support explained significant variations in fostering intrapreneurship behaviour. In another study by Rutherford and Holt (2007), it was found that the way leaders promote intrapreneurship and the diffusion of an entrepreneurial mindset within the organization will influence the employees' behaviour. Management support in the form of supporting for change can encourage the employees to embrace intrapreneurship culture within an organization. As such it is hypothesized that:

H1a: Strong management support will have a significant positive effect on intrapreneurship.

\section{Work Discretion}

Work discretion or sometimes termed as autonomy reflects "the top-level managers' commitment to tolerate failure, provide decision making latitude and freedom from excessive oversight, and to delegate responsibility and authority to middle-level managers" (Kuratko, Ireland et al., 2008, p. 703). It has been found that the autonomy or freedom to make own judgment given by the top management appeared to be an important element to trigger innovativeness (Rutherford \& Holt, 2007). According to Jong and Wennekers (2008), the psychological ownership, which is the subjective feeling of individuals, is formed by having control of one's job, having feelings of efficacy, investing time, ideas and energy (self-investment) in specific organizational factor. As such, in propagating intrapreneurial behaviour among the workforce, it is vital for organisations to allow employees to make decisions about their work process and avoid criticising them if mistakes occur while innovating (Kuratko \& Hodgetss, 2007). This kind of organisational architecture is seen conducive to fostering intrapreneurial spirit among workforce in an organisation. As such, it is postulated that:

H1b: Work discretion will have a significant positive effect on intrapreneurship.

\section{Reward and Reinforcement}

According to De Jong and Wennekers (2008), the availability of reward and resources is one of the important factors that could encourage intrapreneurship. Time, physical and financial resources are required to facilitate individuals within the organization to be involved in innovative activities. As proposed by Chang (1998), intrapreneurship may be influenced by organizational resources which are related to organizations size. Organizations that are large have abundant resources, they thus can create the propensity to utilise intrapreneurship skills in product innovation. Gilberstson (2002) argues that innovation involves a range of activities which is very sensitive to resource allocation processes. Resources in this sense comprise of the authority to spend, access to the information needed and bootlegging time. In addition, De Jong and Hartog (2007) note that to stimulate innovative behaviours, allocating necessary time and money are essential to implement the ideas generated by the innovative employees. Thus, the leaders should provide sufficient funding and other resources to encourage innovation behaviour. Besides, financial or material rewards also have been proved to have the influence on new ideas generation and application. In addition, Bhardwarj, Sushil and Momaya (2007) also notice that one of 
the drivers of corporate entrepreneurship is rewards given to the well performing employees. Rewards can be in terms of recognition, appraisal or monetary factors. Thus to succeed in promoting corporate entrepreneurship, rewards system needs to be properly designed and structured so as to entice and motivate the workforce to behave intrapreneurially. Based on the preceding argument, it is hypothesized that:

H1c: Reward and reinforcement will have a significant positive effect on intrapreneurship.

\section{Time Availability}

In order to foster innovative behaviour, organization must evaluate the workloads of the employees to ensure that the workforce have the time needed to pursue innovation (Kuratko, Ireland et al., 2008). In addition, their jobs should be structured in a manner that it supports the achievement of organizational goals. It is vital for the organization to moderate the workload, avoid putting constraints on all aspects of the employees' job and allow the people to work with others. More importantly, previous studies have consistently reported the importance of time availability in predicting intrapreneurship behaviour (or corporate entrepreneurship) (e.g., Hornsby, Kuratko, \& Montagno, 1999; Kuratko, Hornsby, Naffziger, \& Montagno, 1993; Kuratko Montagno, \& Hornsby, 1990; Slevin \& Covin, 1997). Therefore, this study postulates that:

H1d: Time availability will have a significant positive effect on intrapreneurship.

\section{Organizational Boundaries}

Organizational boundaries are referred to as "precise explanations of outcomes expected from organizational work and development of mechanisms for evaluating, selecting, and using innovations" (Kuratko et al., p. 704). In fostering intrapreneurship behaviour, employees must be encouraged to look at the organization from a broad perspective. As such, top-level managers should avoid having standard operating procedures for all major parts of jobs and should reduce dependence on narrow descriptions and rigid performance standards. In flexible organizational boundaries such as having work autonomy (discretion) in performing the task or decision making, the absence of standard operating procedures, written rules and administrative processes as well as supportive organizational structure can encourage the intrapreneurial behaviors (Bhardwarj, Sushil \& Momaya, 2007). Based on this argument, it can be hypothezised that:

H1e: The absence of organizational boundaries will have a significant positive effect on intrapreneurship.

\section{Intrapreneurial Behaviour and Job Performance}

Intrapreneurial behaviours among employees have always been associated with positive results, be it at individual level or organizational level. For the individual, the outcome is often related to higher job satisfaction and greater commitment at workplace (Holt, Rutherford, \& Clohessy, 2007) whereas at the organizational level, the positive results typically come in the form of objective profitability and better firm performance (e.g., Zahra \& Covin, 1995; Zahra \& Garvis, 2000). Lumpkin and Dess (2005), in proposing a framework for investigating the link between corporate entrepreneurship (intrapreneurial behaviour) and firm performance, argue that while financial measures of performance such as growth, market share and profitability are important; additional, non-financial measures may be just as important in the study of entrepreneurial outcomes. The satisfaction and commitment of organizational members were among the non-financial factors suggested by Lumpkin and Dess (2005). Job satisfaction and affective commitment both represent pleasurable or favorable emotional state derived from an evaluation of one's job or job experiences and employee's emotional attachment to his or 
her organization. Both satisfaction and commitment have been related to higher levels of motivation which could be translated into higher job performance among the employees. High job performance at the individual level will subsequently result in greater organizational effectiveness. This study therefore postulates that:

H2: Intrapreneurial behaviour will have a positive significant effect on job performance.

\section{Methodology}

\section{Sample}

Five hundred self-administered questionnaires were distributed to the respondents in different manufacturing organizations in the Northern Region of Malaysia, of which, 263 questionnaires were found usable. Of 263 respondents, $59.2 \%$ are males and $40.8 \%$ are females. Chinese respondents make up $76 \%$ of the total respondents followed by Malays $(17.4 \%)$ and Indians $(0.5 \%)$. With regards to the job position of respondents in the present organization, $3.3 \%$ are managers and supervisors, $88.7 \%$ are engineers and $8 \%$ are programmers. In terms of the number of years working in the present organization, $24.9 \%$ of the respondents have served less than a year, $43.2 \%$ are between one to three years, $19.2 \%$ are between four to six years and only $12.7 \%$ have served the organization for more than six years. With respect to the nature of business, the majority of the organizations are manufacturing semiconductors (33.8\%), followed by $31 \%$ hard drive and personal computers, $21.6 \%$ two-way radio product and only $13.6 \%$ high end steel and precision tools.

\section{Measurement}

The organizational architecture which consists of management support, work discretion, reward and reinforcement, time availability and organizational boundaries were measured using the Corporate Entrepreneurship Assessment Instrument (CEAI) developed by Kuratko and Hornsby
(2008). Participants responded to the CEAI items using a five-point Likert-type scale, with $1=$ "representing strongly disagree" and $5=$ "representing strongly agree". Management support was measured with 19 items (e.g., "Upper management is aware and very receptive to my ideas and suggestions."). Work discretion was measured with ten items (e.g., "This organization provides freedom to use my own judgment."). Rewards and reinforcement were measured with 6 items (e.g., "The rewards I receive are dependent upon my work on the job."). Time availability was measured with 6 items (e.g., "I always have plenty of time to get everything done."). Finally, organizational boundaries were measured with 7 items (e.g., "On my job, I have no doubt what is expected of me."). Intrapreneurial behaviour which includes innovativeness elements is measured using a 10 -item instrument developed by De Jong (2007). Similarly, responses to these items were made on a 5 -point response format (" $1=$ strongly disagree" to " $5=$ strongly agree"). Finally, items for job performance were adapted from Becker et al., (1996) and Janssen (2001). Similarly, responses to these items were made on a 5-point response format (" $1=$ strongly disagree" to " $5=$ strongly agree").

\section{Result and Findings}

Confirmatory factor analysis (CFA) was performed to examine the factorial validity of the factors and to assess the goodness of fit of the model (Byrne, 2001).

The model was then tested using the structural equation modeling (SEM) procedure. Besides fit statistics, of particular interest is the path significance indicated by the standardised regression estimate $(\beta)$ that assesses the effects of the studied variables. The central point in analysing structural models is the extent to which the hypothesised model "fits" or adequately describes the sample data (Byrne, 2001). A model fit can be evaluated by examining several fit indices which include: chi-square $(\chi 2)$, chi-square/degree of freedom $(\chi 2 / \mathrm{df})$, Goodness-of-Fit Index (GFI) , Tucker Lewis Index (TLI), 
Comparative Fit Index (CFI), Standardized Root Mean Residual (SRMR) and Root Mean Square Error of Approximation (RMSEA). Besides fit statistics, of particular interest is the path significance indicated by the standardised regression estimate $(\beta)$ that assesses the effect of one variable on another. The significance level was set at $\mathrm{p}$ $<.05$. Prior to testing the model, the psychometric properties and the goodness of fit of the constructs studied were undertaken.

The results of CFA analysis suggest that the factor loadings for all major variables range between 0.63 and 0.91 . The Cronbach alpha values reported for the variables are as follows: management support $=0.82$, work discretion $=0.77$, reward and reinforcement $=0.81$, time availability $=$ 0.78, Organizational Boundaries $=0.76$, Intrapreneurial Behaviour $=0.94$ and job performance $=0.79$. The model was then tested using the structural equation modeling (SEM) procedure. The central point in analysing structural models is the extent to which the hypothesised model "fits" or adequately describes the sample data (Byrne, 2001). As shown in Table 3, the model yielded a moderate fit given the sample data of $\chi^{2}=13.45, p=.009, \chi^{2} / d f=$ $3.363, \mathrm{GFI}=.986, \mathrm{IFI}=.953, \mathrm{CFI}=.987, \mathrm{TLI}$ $=.934$ and RMSEA $=.062$.

An analysis of the data using the structural equation modeling procedure, as depicted in Figure 1, shows significant direct effects of management support $(\beta=.33, p<.001)$, work discretion $(\beta=.32, p<.001)$, reward and reinforcement $(\beta=.14, p<.05)$ and time availability $(\beta=.15, p<.05)$. The effect of organizational boundaries on intrapreneurial behaviour however is nonsignificant. The four independent variables account for $58 \%$ of the intrapreneurial behaviour variance. In addition, the effect of intrapreneurial behaviour on job performance is also found significant $(\beta=$ $.65, p<.001)$ and the variable accounts for $42 \%$ of the job performance variance.

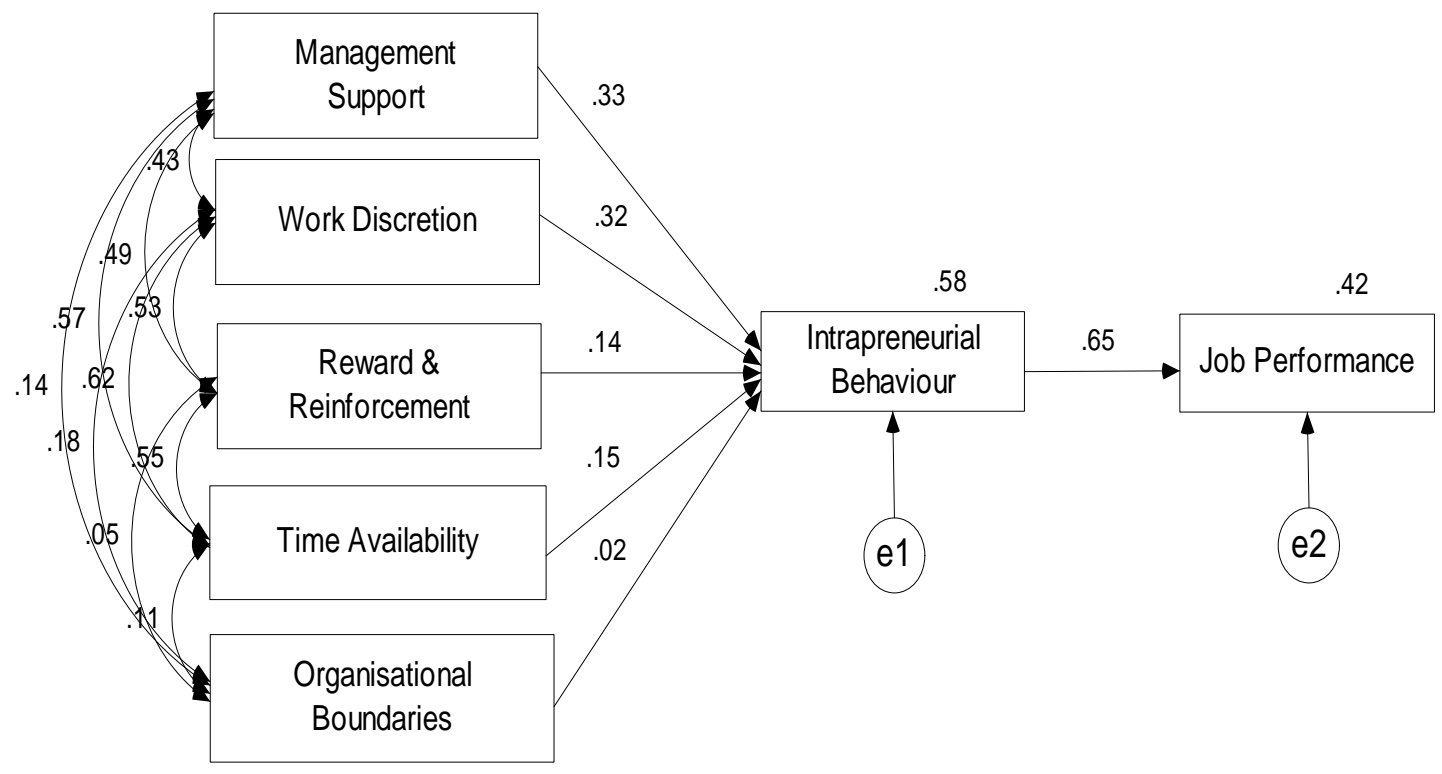

Fig 1. Structural Equation Modeling Procedure

\section{Discussion and Implications}

The value of this study lies in its effort to relate intrapreneurial behaviour towards Transformation agenda of Malaysian society as highlighted in the New Economic Model and Vision 2020. Even though the subject matter may not be unconventional, the prime focus is the practical contribution onto the context of Malaysia's human capital development. Based on the findings, the factors at organizational level that could be structured to spur intrapreneurial behaviours include 
management support, work discretion, resource and reinforcement and time availability. Clearly, this study confirms the previous research that advocates the vital role of pro-intrapreneurship organizational architecture to invigorate intrapreneurial spirit among the workforce (see for example, Bhardwarj, Sushil \& Momaya, 2007; Holt, Rutherford \& Clohessy, 2007; Hornsby, Kuratko, \& Zahra, 2002; De Jong \& Hartog , 2007). Surprisingly however, the effect of low organizational boundaries on intrapreneurship behaviours is nonsignificant. This may be due to the nature of tasks within the organizations that require the employees to follow standard operating procedures and that there are many written rules and procedures that exist. It is also possible that in these organizations, there exists the job description that clearly specifies the standards of performance on which the job is evaluated. With the existence of such organizational boundaries, the employees do not have much flexibility in pursuing entrepreneurial initiatives and thus may have contributed to the non-significant findings. Also, the present study attests the significant positive effect of intrapreneurial behaviour on job performance.

The findings of this study have some important implications on organizations in their efforts to stimulate intrapreneurship. Insights obtained from this study will not only assist organizations to achieve competitiveness and sustainability in the dynamic business environment, but also to contribute to strengthening future economy in the country. In realising the transformation of Malaysia's economy, the private sectors especially manufacturing sector should foster intrapreneurial behaviours among the workforce to boost creativity and innovativeness and subsequently achieve organizational competitiveness.

Importantly, this study provides a clear direction to the top-level management of the organization in shaping intrapreneurial behaviour among the employees. The availability of management support, work discretion, resource and reinforcement and time availability have been proved to have significant influences on intrapreneurship. Based on these empirical findings, the toplevel management should be cognisant of the fact that they should concentrate more on empowerment, flexibility in crafting organizational policies, provide necessary support and act positively to the innovative activities by encouraging risk taking initiatives among the employees. In addition, the management should also design appropriate reward system such as financial reward, recognition and appraisal on significant achievements. The organization should also ensure the availability of resources such as time, materials and funds in supporting new ideas. In short, it can be surmised that the main focus is to structure prointrapreneurship organizational architecture by taking into considerations the factors that could invigorate such behaviours. Forming an internal ecosystem that is conducive for the workforce to behave intrapreneurially within an organization is a wise step to foster innovativeness culture that could subsequently be translated into long term growth and sustainability of the respective organization.

This study is not without limitation. Firstly, convenience sampling was utilised, thus may not permit generalisation of the findings to the whole population. Secondly, while this research makes valuable contributions, the data collection process depends merely on self-report data. This approach, even though criticised by some, was deemed necessary because of difficulties associated with the independent assessment of each of these variables. Furthermore, self-report is not uncommon in studies examining management behaviour.

\section{Conclusion}

As stated at the outset, this study seeks to probe into the pro-intrapereneurship organizational architecture that could be designed in the organizations to enhance job performance of the employees. Notably, in a dynamic and competitive business environment, the organization as well as the country is forced to foster 
intrapreneurial behaviour in order to grow and sustain its competitiveness. This study suggests that the appropriate human resource management practices and flexible organizational structure could be crafted to create intrapreneurshipconducive environment. In short, this study provides valuable insights into ways in which the top management within an organization to strategise and encourage innovative practices and initiatives successfully.

\section{References}

Antoncic, B. \& Hisrich, R. D. (2003). "Clarifying the Intrapreneurship Concept," Journal of Small Business and Enterprise Development, 10(1), 7-24.

Atkinson, A. (1998). "Strategic Performance Measurement and Incentive Compensation," European Management Journal, 16(5), 552-561.

Becker, T. E., Billings, R. S., Eveleth, D. M. \& Gilbert, N. L. (1996). "Foci and Bases of Employee Commitment: Implications for Job Performance," Academy of Management Journal, 39 (2), 464-482.

Belanger, F. (1999). "Workers' Propensity to Telecommute: An Empirical Study," Information \& Management, 35, 139-153.

Bhardwarj, B. R., Sushil. \& Momaya, K. (2007). "Corporate Entrepreneurship: Application of Moderator Method," Singapore Management Review, 29 (1), 4758.

Byrne, B. M. (2001). 'Structural Equation Modeling with AMOS: Basic Concepts, Applications, and Programming,' Mahwah, NJ: Lawrence Erlbaum Associates, Inc.

Chang, J. (1998). "Model of Corporate Entrepreneurship: Intrapreneurship and Exopreneurship," Borneo Review, 9 (2)187212.

de Jong, J. P. J. (2007). "Individual Innovation: The Connection Between Leadership and Employees' Innovative
Work Behaviour," Phd Thesis, Zoetermeer: EIM.

de Jong, J. P. J. \& Hartog, D. N. (2007). “How Leaders Influence Employees' Innovative Behaviour," European Journal of Innovation Management, 10 (1), 41-64.

de Jong, J. P. J., Parker, S. K., Wennekers, S. \& Wu, C. (2011). "Corporate Entrepreneurship at the Individual Level: Measurement and Determinants," EIM Research Reports H201108, p. 1-27.

de Jong, J. \& Wennekers, S. (2008). "Intrapreneurship: Conceptualizing Entrepreneurial Employee Behaviour," Scales Research Reports H200802, EIM Business and Policy Research.

Dess, G. G. \& Lumpkin, G. T. (2005). “The Role of Entrepreneurial Orientation in Stimulating Corporate Entrepreneurship," Academy of Management Executive, 19 (1), 147-156.

Gilbertson, D. (2002). "Public Service Innovation Concepts," Innovative Processes Ltd.

Holt, D. T., Rutherford, W. M. \& Chohessy. G. R. (2007). "Corporate Entrepreneurship: An Empirical Look at Individual Characteristics, Context and Process," Journal of Leadership \& Organizational, 13 (4), 40-54.

Hornsby, J. S., Kuratko, D. F. \& Zahra. S. A. (2002). "Middle Managers' Perception of the Internal Environment for Corporate Entrepreneurship: Assessing a Measurement Scale," Journal of Business Venturing, 17, 253-273.

Ivancevich, J. M., Konopaske, R. \& Matteson, M. T. (2005). Organizational Behavior and Management (7th ed.), New York, NY: McGraw-Hill/Irwin.

Janssen, O. (2001). "Fairness Perceptions as a Moderator in the Curvilinear Relationships between Job Demands, and Job Performance and Job Satisfaction," Academy of Management Journal, 44 (5), 1039-1050. 
9 Journal of Innovation Management in Small \& Medium Enterprises

Kuratko, D. F., Ireland, R. D, Covin, J. G. \& Hornsby, J. S. (2005). "A Model of Middlelevel Managers' Entrepreneurial Behaviour," Entrepreneurship Theory and Practice, November, 699-716.

Kuratko, D. F., Montagno, R. V. \& Hornsby, J. S. (1990). "Developing an Intrapreneurial Assessment Instrument for an Effective Corporate Entrepreneurial Environment," Strategic Management Journal, 11, 49-58.

National Economic Advisory (2010), 'Economic Transformation Programme Report,' [Online], [Retrieved May 15, 2010], http://www.neac.gov.my/node/80

Rutherford, M. W. \& Holt, D. T. (2007). "Corporate Entrepreneurship: An Empirical Look at the Innovativeness Dimension and its Antecedents," Journal of Organisational Change Management, 20 (3), 429-446.

World Economic Forum (2011). "Global Competitiveness Report 2010-2011" [Online], [Retrieved October 21, 2011], http://www3.weforum.org/docs/WEF_Glo balCompetitivenessReport_2010-11.pdf

Wunderer, R. (2001). "Employees as "Cointrapreneurs"- A Transformation Concept," Leadership \& Organization, 22 (5), 193-211. 